\title{
Indicador de competitividad municipal en el Estado de México para construir un entorno competitivo
}

\section{Municipal competitiveness indicator in the State of Mexico for building a competitive environment}

\author{
Rosa María Nava-Rogel* \\ Daniel Arturo Cernas-Ortiz * \\ Osvaldo Urbano Becerril-Torres*
}

\begin{abstract}
Competitiveness indexes are important at a municipal level if they are used to develop public policies that promote a more competitive environment. This study identifies strengths and weaknesses in similar municipalities from the State of Mexico with the help of building an indicator of municipal competitiveness to propose strategies that generate a competitive environment. The municipalities with the highest strengths develop commerce activities and they are near urban areas, while the poorest are agricultural in rural areas. It was concluded that government, business, and society must interact to build a competitive environment.
\end{abstract}

Keywords: indicator, competitiveness, municipality.

\section{Resumen}

Los indicadores de competitividad son importantes a nivel municipal si son usados para desarrollar políticas públicas que impulsen un entorno más competitivo. Este estudio identifica fortalezas y debilidades de municipios del Estado de México, con características similares, a partir de la generación de un indicador de competitividad municipal. Los municipios con mayores fortalezas son los comerciales y cercanos a zonas urbanas, mientras que los más desfavorecidos son los agrícolas en zonas rurales. Se concluye que para construir un entorno más competitivo se requiere la interacción del gobierno, empresas y sociedad.

Palabras clave: indicador, competitividad, municipio.

*Universidad Autónoma del Estado de México, correos-e: rmnavar@uaemex.mx; danielarturoc@ yahoo.com.mx; osvalbt@hotmail.com 


\section{Introducción}

Desde hace algunos años, las clasificaciones de competitividad se han utilizado como información clave en naciones y empresas que pretenden establecer relaciones comerciales o invertir en algún país (Jiménez-García et al., 2011), por ello han surgido organismos e instituciones que sugieren la inclusión de varios factores para medir los niveles de competitividad y compararlos entre naciones (IMD, 2013, Schwab, 2013). A nivel estatal y municipal, medir la competitividad adquiere importancia si a partir de los parámetros utilizados se genera un mapa sobre las fortalezas y debilidades de cada región para generar políticas públicas que impulsen su desarrollo (Cabrero et al., 2003). Al respecto, el Programa de las Naciones Unidas para el Desarrollo (PNUD, 2004) señala que si ese mapa es el apoyo para generar estrategias que impulsen la democracia, riqueza y equidad, puede servir para la generación de competitividad.

Por lo anterior, es pertinente analizar las actividades económicas que realizan los municipios en pro de una mayor calidad de vida entre sus habitantes. En México, sólo algunos municipios generan mejores condiciones competitivas cuando destacan en su vocación económica; en la mayoría de los municipios se desarrollan actividades incipientes que poco contribuyen a la calidad de vida de sus habitantes. Además, la densidad de población, la ubicación geográfica, los usos y costumbres de cada municipio (Linares-Zarco, 2012), el grado de democratización y la vocación hacia la innovación (Millán-Valenzuela y García-Pérez, 2017) son algunas de las características que aceleran o frenan la generación de un contexto competitivo que apoya en el desarrollo municipal.

En este tenor, existen sólo algunos estudios sobre competitividad municipal como el del Instituto Mexicano para la Competitividad (Imco, 2010) ${ }^{1}$ y el de Guillermo-Peón y García-Pérez (2015), quienes desarrollaron un índice para ciudades competitivas y municipios urbanos, respectivamente, pero su objetivo se limitó a mostrar la situación en las ciudades más importantes del país, esto es, no se consideraron todos municipios; por esta razón, aquellos municipios con características rurales ni siquiera se mencionan. Rubí-Salazar (2007) construyó un índice de competitividad para los municipios del Estado de México a partir de siete factores obtenidos de un análisis factorial. Su propósito fue proponer una metodología que sirviera de base para el desarrollo de políticas públicas generalizadas para todo el Estado, no es posible detectar fortalezas

\footnotetext{
${ }^{1}$ El Imco (Instituto Mexicano para la Competitividad A. C.) es el órgano oficial en México para medir la competitividad estatal.
} 
y debilidades en municipios similares porque la población de estudio tiene características heterogéneas.

Velázquez et al. (2011) hacen un análisis minucioso sobre competitividad regional y empresarial de los siete municipios de la zona conurbada del Estado de México, explican el impacto del entorno competitivo empresarial y del desempeño gubernamental en la competitividad de esos lugares. Al realizar dicho estudio, específicamente sobre circunscripciones equivalentes en cuanto a ubicación geográfica y actividad económica, dejan claro que los parámetros comparativos en materia de competitividad municipal deben realizarse entre los que tienen características similares.

Esta investigación tuvo el propósito de identificar fortalezas y debilidades de municipios del Estado de México con características similares, a partir de la generación de un indicador de competitividad municipal, para proponer estrategias que apoyen en la construcción de un entorno competitivo. Para ello, se analizaron investigaciones a propósito de indicadores municipales y regionales, los cuales identifican factores que explican la competitividad a esos niveles. Se consideraron y reunieron datos estadísticos municipales generados por el Inegi; con apoyo de un análisis clúster, se seleccionaron los indicadores de mayor impacto agrupando 13 factores, con ellos se generó un índice de competitividad municipal. A partir de la ubicación geográfica y de los sectores productivos más importantes en cada circunscripción, se congregaron siete grupos para determinar fortalezas y debilidades en municipios similares.

Con base en los hallazgos de este estudio, se afirma que la medición de competitividad municipal requiere considerar características y recursos particulares en cada municipio, para desarrollar estrategias más precisas que incrementen sus fortalezas y reduzcan sus debilidades en pro de una mayor infraestructura competitiva y, por ende, del bienestar de sus habitantes.

\section{Competitividad regional}

El concepto de competitividad regional tiene distintas connotaciones, dependiendo de la perspectiva que se utilice (Esser et al., 1996). Sin embargo, se clarifica el concepto al considerar el punto de vista de varios autores.

Para Porter (1991) es un proceso de generación y difusión de competencias que depende de los factores macroeconómicos y de las capacidades que ofrece el territorio para facilitar las actividades económicas, lo cual genera en el espacio un entorno físico, tecnológico, social, ambiental e institucional propicio para atraer y desarrollar actividades económicas generadoras de riqueza y empleo, es decir, ventajas competitivas. 
Romo y Musik (2005) afirman que la competitividad tiene que ver con la capacidad de crear un entorno que favorezca el crecimiento sostenido de la productividad y que refleje el incremento en el nivel de vida de la población, con el reconocimiento de que los actores están a nivel macro y micro, pero sólo por un vínculo de causa-efecto en el que las acciones del Estado afectan a la población.

Peñaloza (2005) menciona algunos componentes de la competitividad que a lo largo del tiempo han estado relacionados con este concepto: división del trabajo, especialización, calidad, capacidad gerencial y financiera, cultura organizacional, productividad y tecnología. Considera la incorporación de otras variables a nivel macroeconómico como políticas públicas, sistema legal, servicios públicos, infraestructura, sistema educativo y equilibrio fiscal, así como variables microeconómicas: desarrollo empresarial, demanda del mercado e innovación.

Las variables referidas contribuyen a explicar la competitividad como un proceso en el que interactúan las capacidades productivas y los agentes económicos, sociales y políticos que existen en una región (IbarraArmenta y Trejo-Nieto, 2014), lo cual genera un contexto competitivo e incrementa las posibilidades de una mayor calidad de vida de las personas. Sin embargo, en los últimos años, han surgido propuestas con otras variables que han cobrado gran relevancia, tal es el caso del dominio del conocimiento (Paulus y Vacchiani-Marcuzzo, 2016), el poder de la información (Önder et al., 2017) y la preservación del medio ambiente (Carvalho, et al., 2017; Taibo, 2009).

El Foro Económico Mundial -WEF por sus siglas en inglés- afirma que la competitividad global es la actitud de un país o empresa para generar más riqueza para su gente que sus competidores (World Economic Forum, 2009). Con ello, el concepto de Martin (2003) cobra sentido: la competitividad es la capacidad de la región para producir bienes y servicios que apoyan el mercado internacional y que, al mismo tiempo, garantiza el mantenimiento de los ingresos altos y estables para sus habitantes, lo cual, necesariamente, debe traducirse en un beneficio general para la sociedad.

El Instituto Mexicano para la Competitividad (Imco, 2016) explica que a nivel regional, uno de los factores más importantes que afecta la competitividad es la administración del territorio, es decir, la planeación, regulación y ejecución de las actividades humanas con impacto sobre el espacio físico-geográfico. Esta afirmación es fundamental para comprender que un indicador de competitividad municipal no debe utilizarse para hacer un comparativo entre todos los municipios, porque cada territorio es diferente en cuanto a las actividades que se realizan, la vocación que siguen y la ubicación geográfica que tienen. Ya lo decía Krugman (1994) 
al advertir el peligro de utilizar la clasificación de competitividad con una visión superficial, en la cual sólo se observan regiones ganadoras y perdedoras. Un indicador de competitividad municipal debe realizarse con la premisa de aportar información que ayude a mejorar el Desarrollo Humano de la Región (PNUD, 2010).

\section{Clasificación de competitividad}

La clasificación de competitividad ha cobrado importancia en los últimos ańos porque resume información valiosa que sirve a naciones y empresas para decidir sobre una posible inversión. Existen dos a nivel mundial que se han reconocido por los criterios que toman: la realizada por el Institute of Management Development (IMD, 2013) y la que elabora el World Economic Forum (WEF, 2015).

El IMD, a través del World Competitiveness Center, realiza un reporte anual desde 1989 sobre 59 países, se basa en medidas de eficiencia en la utilización de recursos, así como en el establecimiento de políticas públicas que logran generar un ambiente y una infraestructura para el desarrollo de la competitividad. Dentro de los cuatro criterios que toma en cuenta destaca el de infraestructura, porque es el criterio que soporta los otros tres por la existencia de una infraestructura de comunicaciones, sanitaria, ecológica y de investigación científica y tecnológica así como educativa; no habrá soporte para desarrollar la economía, la eficiencia empresarial y la gubernamental.

Por su parte, el WEF realiza un análisis sobre los requerimientos básicos para generar competitividad -reforzadores de eficiencia, sofisticación e innovación- y los compara en 148 países para establecer su propia clasificación. La metodología para realizar esta clasificación es más sofisticada y más completa porque considera variables ausentes en el IMD, tal es el caso de la estabilidad macroeconómica, la educación dividida en educación básica y superior, la eficiencia del mercado, dividida en mercado de bienes, laboral y financiero, entre otros.

Ambos organismos tienen el propósito de mostrar a los políticos, posibles inversionistas y en general a toda la comunidad, las fortalezas y debilidades de cada país. Incluso se desarrollan estudios especializados por continentes y países, a partir de comparativos. Estos análisis han dado pie a que se realicen varios estudios a nivel regional sobre las condiciones competitivas de cada estado y región. 


\section{Indicadores de competitividad regional}

Existen varios estudios sobre competitividad regional que han analizado factores determinantes de las diferencias entre las regiones más y menos competitivas. Benzaquen et al. (2010) consideran cinco pilares para construir un índice de competitividad regional en cualquier país: 1 . gobierno e instituciones, 2. desarrollo económico, 3. infraestructura productiva, 4. capital humano y 5 . eficiencia de las empresas; recomiendan que los índices seleccionados se estandaricen para considerar unidades de medida equivalentes que permitan obtener un resultado global del índice, así como los resultados parciales y los resultados parciales para cada pilar. Este estudio es un referente teórico, pero no se ha utilizado para generar un indicador regional.

Uno de los primeros trabajos con soporte teórico que ha desembocado en la generación de un indicador regional es el presentado por el Departamento de Negocios, Tratados e Inversión de Irlanda (Bonner, 2007), que realiza un comparativo entre las regiones de ese país; asignan un peso específico a 18 indicadores, de acuerdo a lo señalado por Huggins (2003), dicho trabajo considera la aportación de la innovación, inversión, habilidades/educación, empresas, desarrollo empresarial e infraestructura económica; los costos en los que incurren las empresas y su repercusión en los indicadores macroeconómicos.

Unos años después, surge un estudio que aporta elementos clave para la generación de un índice regional denominado Índice de Competitividad Regional (RCI, por sus siglas en inglés) (Annoni y Dijkstra, 2013; Annoni y Kozovska, 2010). En él se hace un comparativo en regiones de Estados Unidos y Europa a partir de 11 pilares: instituciones, estabilidad macroeconómica, infraestructura, salud, calidad de educación básica, educación superior, eficiencia del mercado laboral, tamaño de mercado, infraestructura tecnológica, sofisticación de los negocios e innovación. Cada pilar consta de una serie de indicadores, considera un total de 48.

En el contexto mexicano, Cabrero et al. (2003) sugieren la construcción de un índice para ciudades mexicanas e identifican dos tipos de ventajas competitivas: 1 . las que son estáticas y que provienen de la localización geográfica, la disponibilidad de infraestructura y los estándares ambientales aceptables y 2 . las ventajas dinámicas, en donde agrupan a los habitantes, la fuerza de trabajo, la capacidad de innovación tecnológica y empresarial, la cooperación empresarial, el gobierno como promotor de desarrollo económico, el entorno institucional y las redes de cooperación entre ciudades y gobiernos.

El estudio de Carrillo (2013) destaca por su estructura metodológica pues, a partir de ella, explica que el desarrollo regional ha sido desequili- 
brado a favor de las regiones más urbanizadas e involucradas en las actividades del intercambio económico y social. Por ello, para Sobrino (2005) y el Imco (2010) toma sentido hacer un comparativo entre las ciudades más desarrolladas. El primero realiza un análisis de las ciudades más competitivas de México, presenta un listado de posición competitiva que incluye la competitividad comercial y de servicios y la participación de cada sector en el valor bruto de la producción. Por su parte, el Imco genera un índice de competitividad urbana, en el que selecciona las principales ciudades de México y las evalúa con los mismos diez factores que consideran para la competitividad estatal. La selección de las ciudades se determina de acuerdo a la existencia de información, quedan fuera de este análisis aquellos municipios que no reúnen las estadísticas específicas. Para el indicador 2016 de las ciudades competitivas, se consideraron 74 ciudades de todo México (Imco, 2016).

Específicamente, para el Estado de México, Rubí-Salazar (2007) publicó un estudio de competitividad municipal, utilizó 32 variables agrupadas en siete factores, pero llega a conclusiones generales sobre la necesidad de reforzar la creación de cadenas industriales en ramas y sectores más competitivos. Más adelante, Velázquez et al. (2011) realizaron un estudio desde una perspectiva regional y empresarial a través de un análisis cualitativo de las fortalezas y debilidades de siete municipios ubicados en la zona urbana de la Ciudad de México, ellos dejan claro que no es válido comparar a todos los municipios con los mismos parámetros.

Todos los estudios sobre competitividad regional consideran diversos factores que interactúan para el desarrollo de un entorno más competitivo. La tabla 1 muestra un comparativo entre dichos factores.

\section{Sobre la situación de los municipios del Estado de México}

El Estado de México es una de las entidades más importantes del país ya que se localiza en el centro de la república mexicana; su cercanía con la Ciudad de México, así como sus condiciones climatológicas, contribuyen a que sea la entidad con más habitantes -sobre todo en la zona conurbada de la capital del país- que contribuye más al Producto Interno Bruto, después de la Ciudad de México (Inegi, 2010).

A pesar de ello, existen marcadas diferencias entre los municipios, mientras que hay algunos altamente industrializados, otros realizan actividades primarias de manera precaria. En el Estado de México se encuentran algunas de las zonas comerciales y habitacionales más lujosas: Huixquilucan y Metepec (Rubí-Salazar, 2007), pero también están algunos de los municipios con mayor número de personas en pobreza como Ecatepec de Morelos, Nezahualcóyotl y Toluca (Coneval, 2014). 


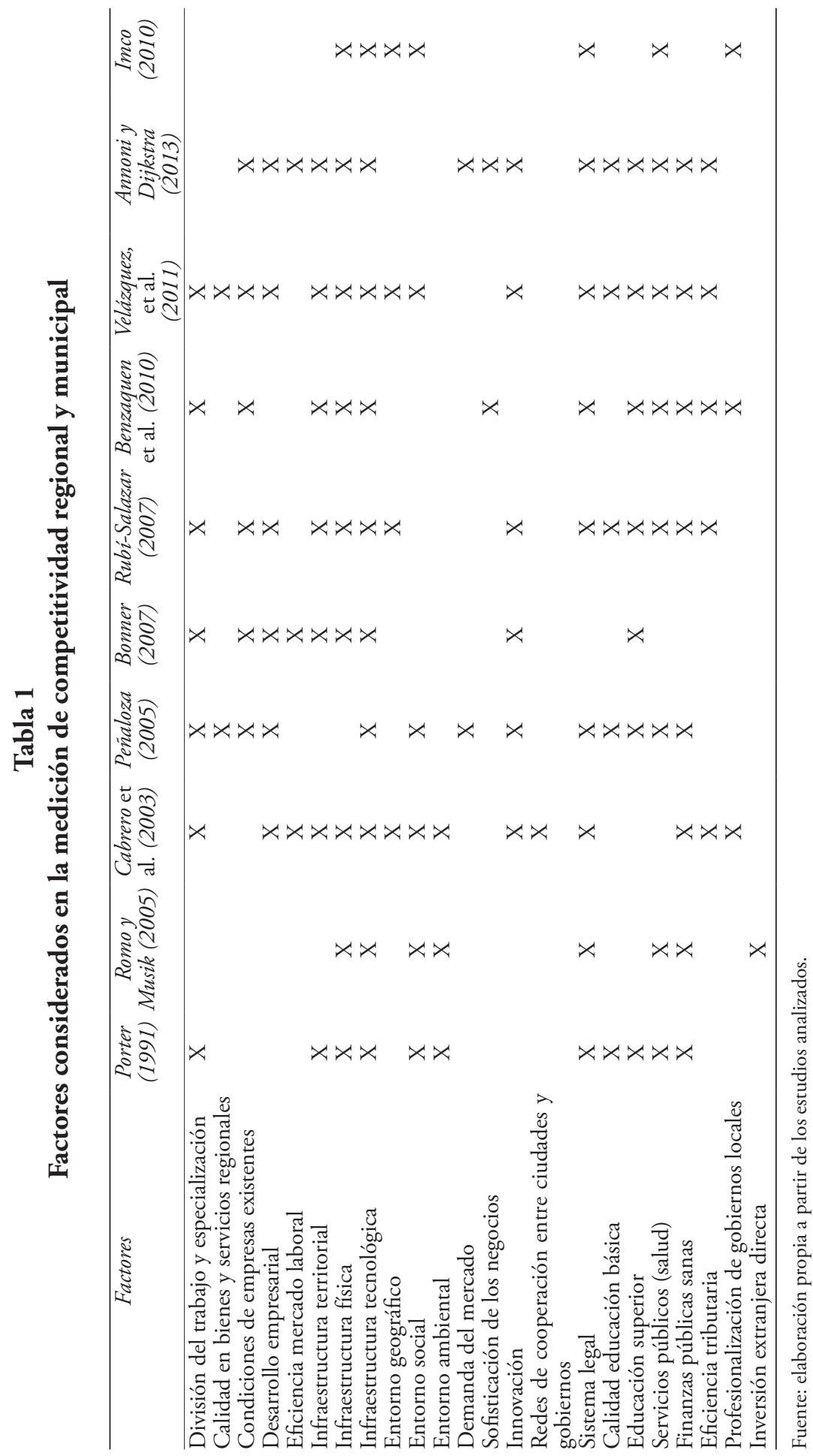


La zona metropolitana de la ciudad capital del Estado de México ha tenido un importante crecimiento en los últimos ańos por su cercanía a la Ciudad de México, pero no se ha hecho de manera ordenada. En resumen, en un estado relativamente pequeño pueden observarse grandes desigualdades sociales y económicas (Rubí-Salazar, 2007).

En cuanto a las actividades económicas que se desarrollan, el Estado de México se caracteriza por su vocación industrial, sobre todo la de tipo manufacturero, que representa $27 \%$ del Producto Interno Bruto (PIB) de este territorio. Las siguientes actividades de mayor importancia por lo que representan en el PIB son el comercio (19\%) y los servicios inmobiliarios y de alquiler (14\%). En contraste, sólo alrededor de 20 municipios sostienen la producción agrícola y ganadera de la región que representa apenas 2\% del PIB (Inegi, 2010).

En la tabla 2 se muestran las diferencias de los municipios del Estado de México considerando la zona geográfica en la que se encuentran y las principales actividades económicas que desarrollan. Como puede observarse, la zona geográfica es altamente influenciable en las actividades económicas, por ello, no existen municipios aledaños a Toluca dedicados exclusivamente a la agricultura y sólo dos hay en la zona conurbada a la Ciudad de México. Por otra parte, como la ciudad capital del Estado de México ha destacado más bien en su actividad industrial, existen ocho municipios colindantes en los que la influencia industrial ha permeado; mientras que en la mayoría de los municipios cercanos a la Ciudad de México se desarrollan actividades manufactureras y comerciales. Las actividades agrícolas y ganaderas se realizan en mayor proporción en las zonas que no están influenciadas por las grandes urbes.

Como en casi todos los estados que conforman la república mexicana, el porcentaje de generación de riqueza se concentra en unos cuantos municipios. De acuerdo con Linares-Zarco (2012), las actividades agropecuarias se concentran en los municipios de Atlacomulco, Coatepec Harinas, Jilotepec, Tejupilco, Texcoco, Toluca, Valle de Bravo y Zumpango; las industriales en Atizapán de Zaragoza, Cuautitlán Izcalli, Lerma, Naucalpan y Tlalnepantla; las comerciales en Ixtapaluca, Ecatepec, Nezahualcóyotl y Toluca; los servicios en Ecatepec, Naucalpan y Tlalnepantla y los de turismo en Ixtapan de la Sal, Valle de Bravo y Metepec, a pesar de que los gobiernos federal y estatal han otorgado apoyos extraordinarios para activar el turismo (Secretaría de Turismo, 2016; Gobierno del Estado de México, 2016). 


\section{Tabla 2 \\ Clasificación de municipios del Estado de México por zona geográfica y actividades}

\begin{tabular}{|c|c|c|c|}
\hline & $\begin{array}{l}\text { Sin influencia } \\
\text { geográfica }\end{array}$ & $\begin{array}{c}\text { Zona Metropolitana de } \\
\text { la Ciudad de México }\end{array}$ & $\begin{array}{l}\text { Zona Metropolitana } \\
\text { del Valle de Toluca }\end{array}$ \\
\hline Agricultura & $\begin{array}{l}\text { Acambay } \\
\text { Ocuilan } \\
\text { Santo Tomás } \\
\text { Tlatlaya } \\
\text { Villa Victoria }\end{array}$ & $\begin{array}{l}\text { Isidro Fabela } \\
\text { Jilotzingo }\end{array}$ & \\
\hline $\begin{array}{l}\text { Agricultura y turismo } \\
\text { con apoyo } \\
\text { económico }\end{array}$ & $\begin{array}{l}\text { Amanalco } \\
\text { Coatepec Harinas } \\
\text { Donato Guerra } \\
\text { Temascaltepec }\end{array}$ & Villa del Carbón & \\
\hline $\begin{array}{l}\text { Agricultura y } \\
\text { manufactura } \\
\text { Agricultura, manu- } \\
\text { factura y turismo con } \\
\text { apoyo económico }\end{array}$ & Aculco & & Ocoyoacac \\
\hline Comercio & $\begin{array}{l}\text { Almoloya de } \\
\text { Alquisiras } \\
\text { Amatepec } \\
\text { Xalatlaco } \\
\text { Jiquipilco } \\
\text { Joquicingo } \\
\text { San Felipe del } \\
\text { Progreso } \\
\text { San Simón de } \\
\text { Guerrero } \\
\text { Tejupilco } \\
\text { Temoaya } \\
\text { Tenancingo } \\
\text { Texcaltitlán } \\
\text { Villa Guerrero } \\
\text { Zumpahuacán } \\
\text { Luvianos } \\
\text { San José del Rincón }\end{array}$ & $\begin{array}{l}\text { Atlautla } \\
\text { Coyotepec } \\
\text { Chalco } \\
\text { Chicoloapan } \\
\text { Chiconcuac } \\
\text { Chimalhuacán } \\
\text { Ecatzingo } \\
\text { Hueypoxtla } \\
\text { Juchitepec } \\
\text { Nicolás Romero } \\
\text { Temamatla } \\
\text { Tenango del Aire } \\
\text { Temascalapa } \\
\text { Tequixquiac } \\
\text { Texcoco } \\
\text { Tonanitla } \\
\text { Valle de Chalco Solida- } \\
\text { ridad }\end{array}$ & Mexicaltzingo \\
\hline $\begin{array}{l}\text { Comercio y turismo } \\
\text { con apoyo } \\
\text { económico }\end{array}$ & $\begin{array}{l}\text { Sultepec } \\
\text { Ixtapan de la Sal } \\
\text { Malinalco } \\
\text { Tonatico }\end{array}$ & $\begin{array}{l}\text { Ozumba } \\
\text { Tepetlixpa } \\
\text { Amecameca } \\
\text { Otumba }\end{array}$ & \\
\hline $\begin{array}{l}\text { Comercio y otros } \\
\text { servicios }\end{array}$ & Otzoloapan & $\begin{array}{l}\text { Coacalco de Berriozá- } \\
\text { bal } \\
\text { Cocotitlán } \\
\text { Nezahualcóyotl } \\
\text { Tecámac } \\
\text { Zumpango }\end{array}$ & \\
\hline
\end{tabular}


Continúa...

\begin{tabular}{|c|c|c|c|}
\hline & $\begin{array}{l}\text { Sin influencia } \\
\text { geográfica }\end{array}$ & $\begin{array}{l}\text { Zona Metropolitana de } \\
\text { la Ciudad de México }\end{array}$ & $\begin{array}{l}\text { Zona Metropolitana } \\
\text { del Valle de Toluca }\end{array}$ \\
\hline $\begin{array}{l}\text { Comercio, otros } \\
\text { servicios y turismo } \\
\text { con apoyo económico }\end{array}$ & El Oro & & Metepec \\
\hline \multirow[t]{10}{*}{ Manufactura } & Almoloya del Río & Apaxco & Lerma \\
\hline & Atlacomulco & Atizapán & \\
\hline & Capulhuac & Cuautitlán & San Antonio la Isla \\
\hline & Jocotitlán & Cuautitlán Izcalli & \\
\hline & Morelos & Chiautla & San Mateo Atenco \\
\hline & Polotitlán & Huehuetoca & \\
\hline & $\begin{array}{l}\text { Soyaniquilpan de } \\
\text { Juárez }\end{array}$ & La Paz & Toluca \\
\hline & Tepetlaoxtoc & Naucalpan de Juárez & \\
\hline & Tianguistenco & Tlalnepantla de Baz & \\
\hline & Timilpan & Tultitlán & \\
\hline \multirow{7}{*}{$\begin{array}{l}\text { Manufactua con } \\
\text { turismo con apoyo } \\
\text { económico }\end{array}$} & Jilotepec & Nopaltepec & \\
\hline & & Papalotla & \\
\hline & & $\begin{array}{l}\text { San Martín de las } \\
\text { Pirámides }\end{array}$ & \\
\hline & Temascalcingo & Tepotzotlán & \\
\hline & & Acolman & \\
\hline & & Teotihuacán & \\
\hline & & Tlalmanalco & \\
\hline \multirow[t]{7}{*}{$\begin{array}{l}\text { Manufactura y } \\
\text { comercio }\end{array}$} & $\begin{array}{l}\text { Atizapán de } \\
\text { Zaragoza }\end{array}$ & Atenco & Almoloya de Juárez \\
\hline & $\begin{array}{l}\text { Chapa de Mota } \\
\text { Ixtlahuaca }\end{array}$ & $\begin{array}{l}\text { Ecatepec de Morelos } \\
\text { Jaltenco }\end{array}$ & \\
\hline & Tenango del Valle & Ixtapaluca & Calimaya \\
\hline & Texcalyacac & Nextlalpan & \\
\hline & & Teoloyucan & \\
\hline & & Tezoyuca & Otzolotepec \\
\hline & & Tultepec & \\
\hline $\begin{array}{l}\text { Manufactura, } \\
\text { comercio y turismo } \\
\text { con apoyo económico }\end{array}$ & & Axapusco & \\
\hline Minería & Zacazonapan & & \\
\hline \multicolumn{4}{|c|}{$\begin{array}{l}\text { Minería y turismo conZacualpan } \\
\text { apoyo económico }\end{array}$} \\
\hline Construcción & Villa de Allende & & \\
\hline Servicios financieros & & Huixquilucan & \\
\hline $\begin{array}{l}\text { Servicios de } \\
\text { transporte }\end{array}$ & & Melchor Ocampo & \\
\hline $\begin{array}{l}\text { Medios masivos de } \\
\text { comunicación }\end{array}$ & & & Rayón \\
\hline $\begin{array}{l}\text { Servicios } \\
\text { inmobiliarios }\end{array}$ & Ixtapan del Oro & & \\
\hline \multicolumn{4}{|c|}{ Servicios inmobiliarios Ayapango } \\
\hline $\begin{array}{l}\text { y turismo con apoyo } \\
\text { económico }\end{array}$ & Valle de Bravo & & \\
\hline
\end{tabular}

Fuente: elaboración propia a partir de los estudios analizados. 
En cuanto a densidad de población, para los municipios cercanos a la Ciudad de México es alta; los que conforman el Valle de Toluca tienen una densidad media y los que están al sur del Estado tienen pocos habitantes (Inegi, 2010). Ante este panorama, se comprende por qué no es conveniente comparar los municipios de la misma manera.

\section{Hacia la construcción de un índice (metodología)}

Los índices de competitividad han cobrado importancia en los últimos años porque facilitan la comparación, la asimilación sobre objetivos y metas y la evaluación de programas específicos (Ronquillo-Rodríguez, 2013) para determinar su impacto (Van Horne et al., 1988), ya que son un instrumento empírico que permite representar la dimensión teórica de una variable clave.

El objetivo de esta investigación fue identificar fortalezas y debilidades de municipios del Estado de México, con características similares, a partir de la generación de un indicador de competitividad municipal para proponer estrategias que apoyen en la construcción de un entorno competitivo. Se realizó una investigación documental utilizando datos secundarios y desarrollando indicadores con base en información estadística disponible en Inegi (2010), con ello se aseguraron datos confiables y homogéneos.

Se realizó una investigación cuantitativa descriptiva porque se recogieron cifras de los 125 municipios del Estado de México para compararlos y describirlos. Este estudio es una investigación aplicada que utilizó teorías ya desarrolladas. En cuanto al diseño de investigación, ésta fue de tipo no experimental porque se observó el fenómeno sin realizar ninguna alteración; fue una investigación transversal que observó un sólo momento en el tiempo. Se tomaron datos de la población de estudio, es decir, los municipios del Estado de México.

Para la construcción del indicador se consideraron las características que debe tener para que sea suficiente y adecuado a la causa que lo origina:

- Tener como base un marco teórico o conceptual (López y Gentile, 2008). En este caso, las bases son los estudios analizados.

- Ser específico (que se vincule con una variable) y explícito (claridad en lo que se está midiendo y en los términos en los que se está midiendo) (Eckerson, 2010).

- Ser relevante y oportuno (Van Horne et al., 1988), verificar la existencia de registros de los 125 municipios del Estado de México, por lo menos para el año 2010. Se dejaron fuera los indicadores 
que sólo existen a nivel estatal o nacional, como la inversión extranjera directa o infraestructura carretera.

- Interpretar y valorar con respecto a los objetivos que se ha establecido (Rodríguez-Yunta, 1998)", en este caso, medir la competitividad municipal de acuerdo a los recursos particulares de cada municipio.

- Recoger información que interprete la realidad del contexto (WEF, 2015), por ello los datos utilizados en esta investigación se obtuvieron de cifras oficiales.

Se calcularon los supuestos de normalidad, linealidad y multicolinealidad (Lévy y Varela, 2003) a partir del coeficiente de correlación parcial $\mathrm{KMO}^{2}$ de Kaiser (1974), que evalúa el nivel explicativo de las puntuaciones de cada una de las variables, midiendo la relación entre dos variables y eliminando la influencia del resto; se determinó que existen 37 indicadores con una correlación entre - 0.8 y 0.8 (Imco, 2016). En ellos se calculó el test de esfericidad de Barlett, obteniendo resultandos favorables con un nivel de significancia menor a 0.005. Bajo el método de Componentes Principales con rotación ${ }^{3}$ se examinaron las características estadísticas implícitas en cada indicador (Martínez-Arias, 1995), identificando 13 factores (tabla 3) que explican el 77.05\% de la varianza acumulada de la competitividad municipal en el Estado de México.

La extracción y rotación de factores permitió eliminar algunos indicadores por su incipiente relación con los demás. Esto, a partir de las comunalidades, en las que se identificaron aquellos indicadores cuya varianza única es menor a 0.5 y que, por consiguiente, son carentes de explicación suficiente en la variabilidad común de la matriz de datos (Lévy y Varela, 2003). De este análisis se extrajeron los factores cuyo valor es mayor a 1, de acuerdo a la Regla de Kaiser-Guttman. ${ }^{4}$

Los 13 factores extraídos recopilan información sobre características de la población, economía, infraestructura, salud, educación, producción, medio ambiente y finanzas. Cada factor fue bautizado de acuerdo a los indicadores agrupados (Fuente de la y Gundín, 2011) (tabla 4).

\footnotetext{
${ }^{2}$ El rango de KMO es de 0 a 1, donde, entre más cerca esté del 1, las variables estarán más relacionadas entre sí. Si las variables comparten factores comunes, el coeficiente de correlación parcial entre pares de variables es bajo, puesto que se eliminan los efectos lineales de las otras variables (Fuente de la y Gundín, 2011). Kaiser (1974) sugiere que la matriz de correlación será útil en las aproximaciones para factorizar si el KMO es igual o mayor a 0.6 (regular), considerando los modelos superiores a 0.8 como buenos.

${ }^{3}$ Se utilizó el método Varimax para minimizar el número de variables con cargas altas en un factor (Thurstone, 1947).

${ }^{4}$ En este estudio fue viable utilizar la Regla de Kaiser-Guttman porque la proporción de sujetos por variable es alta (Ruiz y San Martín, 1992).
} 


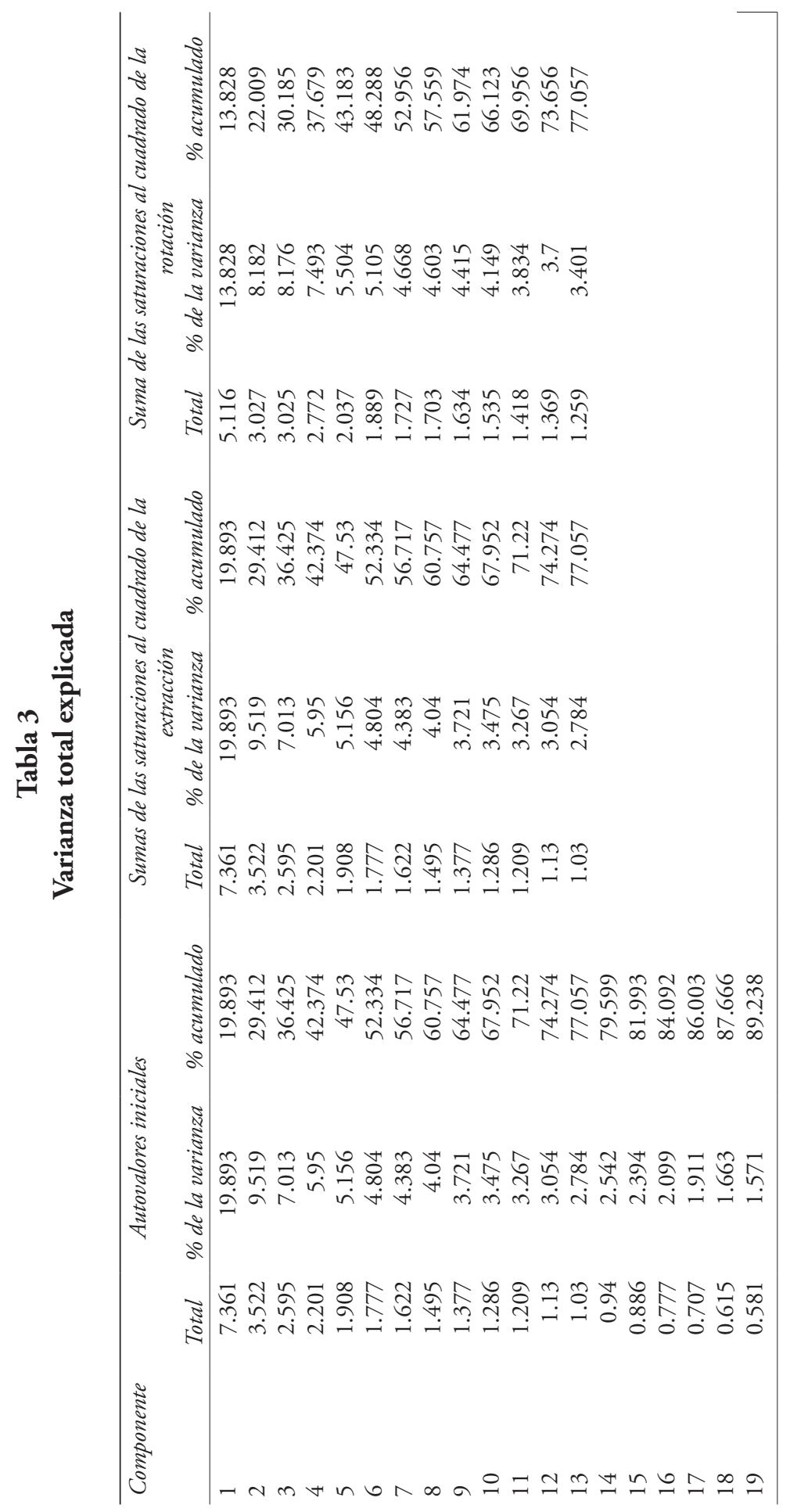




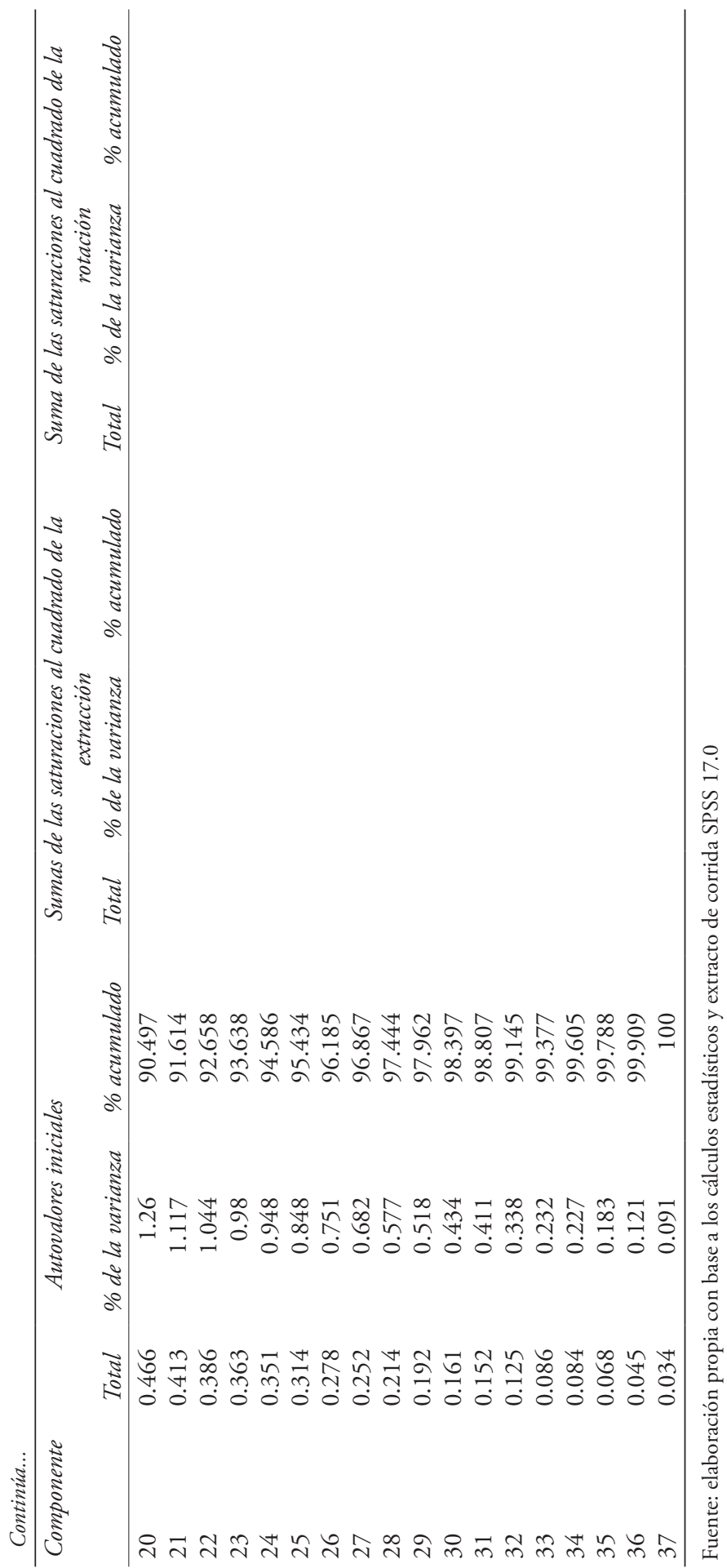




\section{Tabla 4}

\section{Factores y sus indicadores}

\begin{tabular}{ll}
\hline \multicolumn{1}{c}{ Factor } & \multicolumn{1}{c}{ Indicadores } \\
\hline 1 Economía, salud, educación & Índice de población de 25 ańos y más con educación \\
superior. & Índice de actividades comerciales, producción bruta \\
& total por PO. \\
& Producción anual obtenida entre superficie cosechada. \\
& Producto Interno Bruto (PIB). \\
& Salarios mínimos. \\
& Indicadores geográficos, densidad de población. \\
& Indicadores sociodemográficos, porcentaje de la PEA. \\
& Indicadores de salud, habitantes por unidad médica. \\
& Indicadores de educación media básica. Alumnos por \\
& escuela. \\
& Indicadores económicos, finanzas, deuda pública \\
municipal per cápita.
\end{tabular}

2 Condiciones de vida en el Índice de marginación. hogar

Población 12 años y mas EA según condición de ocupación / PEA.

Viviendas particulares con energía eléctrica / viviendas particulares.

Viviendas particulares con agua de red pública / viviendas particulares.

3 Infraestructura, ingresos y Índice de envejecimiento total. envejecimiento.

Finanzas públicas, ingresos municipales.

Indicadores de infraestructura, $\mathrm{km}$ de caminos por cada mil habitantes.

4 Actividades manufactureras Índice de actividades manufactureras, total de activos del sector industrial fijos.

Índice de actividades manufactureras, producción bruta total por persona ocupada.

5 Uso industrial y residencial de Usuarios del servicio eléctrico industrial entre poblala electricidad ción total.

Usuarios del servicio eléctrico residencial entre población total.

6 Salud pública e ingresos mu- Indicadores de salud, consultas por médico. nicipales

Indicadores de salud, consultas por unidad médica. Tasa de crecimiento de ingresos municipales.

7 Crecimiento del PIB y PIB PIB por sector primario entre población ocupada. sector primario Tasa de crecimiento del PIB.

8 Valor agregado censal y PIB PIB por sector servicios entre población ocupada. sector industrial Valor agregado censal bruto por persona ocupada.

9 Infraestructura eléctrica e in- Ingresos por servicio eléctrico. versión pública Infraestructura energía eléctrica. Inversión pública per cápita.

10 Medio ambiente y salud Superficie reforestada. Indicadores de salud, habitantes por unidad médica. Tasa bruta de mortalidad infantil.

11 PIB Sector industrial PIB por sector industrial entre población ocupada.

12 Crecimiento de egresos Tasa de crecimiento de egresos municipales ejercidos. 13 Alumnos / maestros Indicadores de educación, alumnos por maestro.

Fuente: elaboración propia con base en cálculos estadísticos. 
Con la definición de los factores que interactúan en la competitividad municipal fue factible considerar la fórmula sugerida por Schwab y Porter (2009) para determinar una calificación por municipio. A partir de ello cada factor fue comparable, en un rango de 1 a 7 en donde 1 es lo mínimo y 7 es lo máximo (ecuación 1).

$$
\text { Calificación }=7 *\left(\frac{\text { valor observado }- \text { minimo }}{\text { maximo }- \text { minimo }}\right)+1
$$

\section{Resultados}

Bajo la visión de que el indicador de competitividad a nivel municipal puede ser la base para identificar fortalezas y debilidades, en la tabla 5 se presentan los indicadores de competitividad municipal y el indicador por grupo de acuerdo a características geográficas y económicas.

$\mathrm{Al}$ realizar un análisis por sectores puede observarse que en el agrícola se benefician los que están en cerca de la Ciudad de México. Sin embargo, los municipios que combinan la actividad agrícola con otra muestran mejores indicadores de competitividad. Destaca el municipio de Ocoyoacac, que ha aprovechado su ubicación, pues está entre la Ciudad de México y Toluca, en esta entidad se combina el sector agrícola y el manufacturero, con ello obtiene la mejor calificación de los municipios del Estado de México.

Para el sector comercial ocurre algo similar: aquellos municipios prioritariamente comerciales que están influenciados por las zonas urbanas tienen mejores resultados que los alejados de ellas; en general, los municipios que combinan el comercio con otra actividad muestran mejores resultados, debido en parte a que en el Valle de Toluca se genera una gran cantidad de actividades comerciales a través de los tradicionales tianguis. No obstante, los municipios comerciales con otra actividad, que han sido apoyados con algún programa turístico, muestran mejores resultados cuando están dentro de la zona urbana, es el caso de Metepec, que ha sabido aprovechar el programa "Pueblo con Encanto", explotando sus atractivos turísticos, comercializando artesanías y aprovechando la gran demanda de viviendas de los habitantes de Toluca y de los que salen de la Ciudad de México.

Por otro lado, los municipios que tienen de manera casi exclusiva la actividad manufactura muestran mejores resultados que los que combinan con otras. Las grandes ventajas de la cercanía con la Ciudad de México, como la infraestructura carretera y las redes comerciales, se han aprovechado desarrollando grandes corredores industriales dentro de las zonas metropolitanas. 


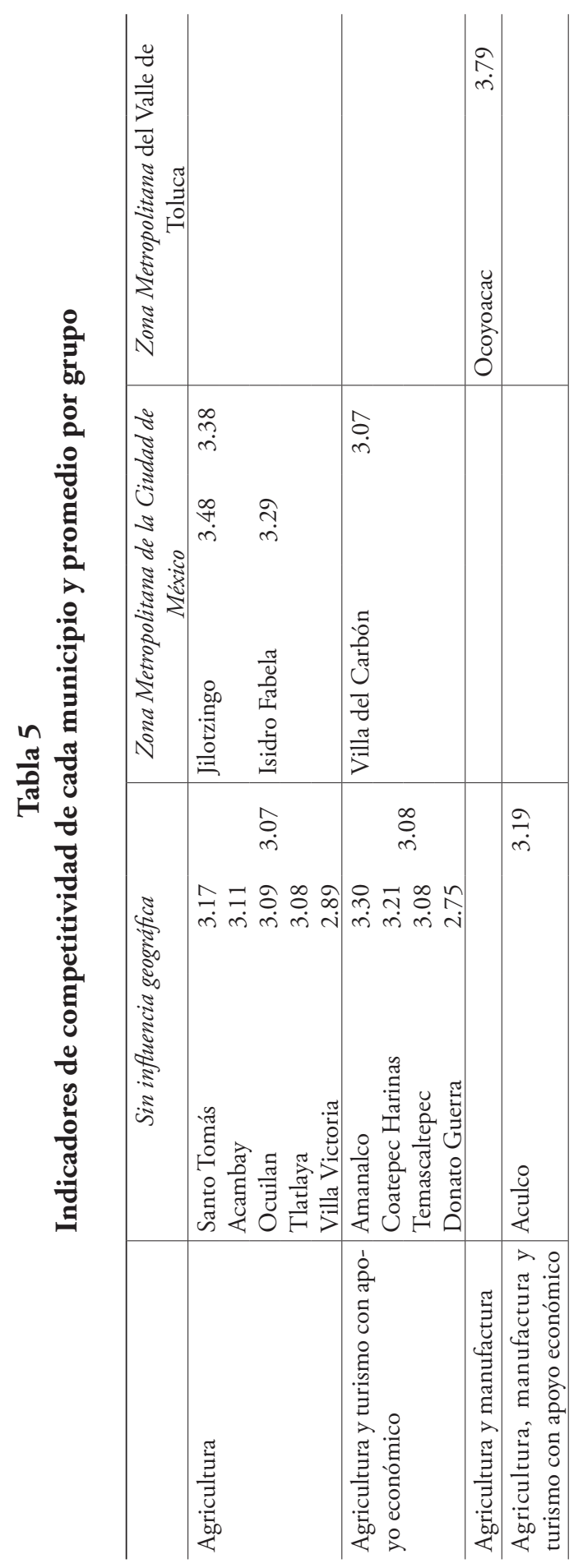




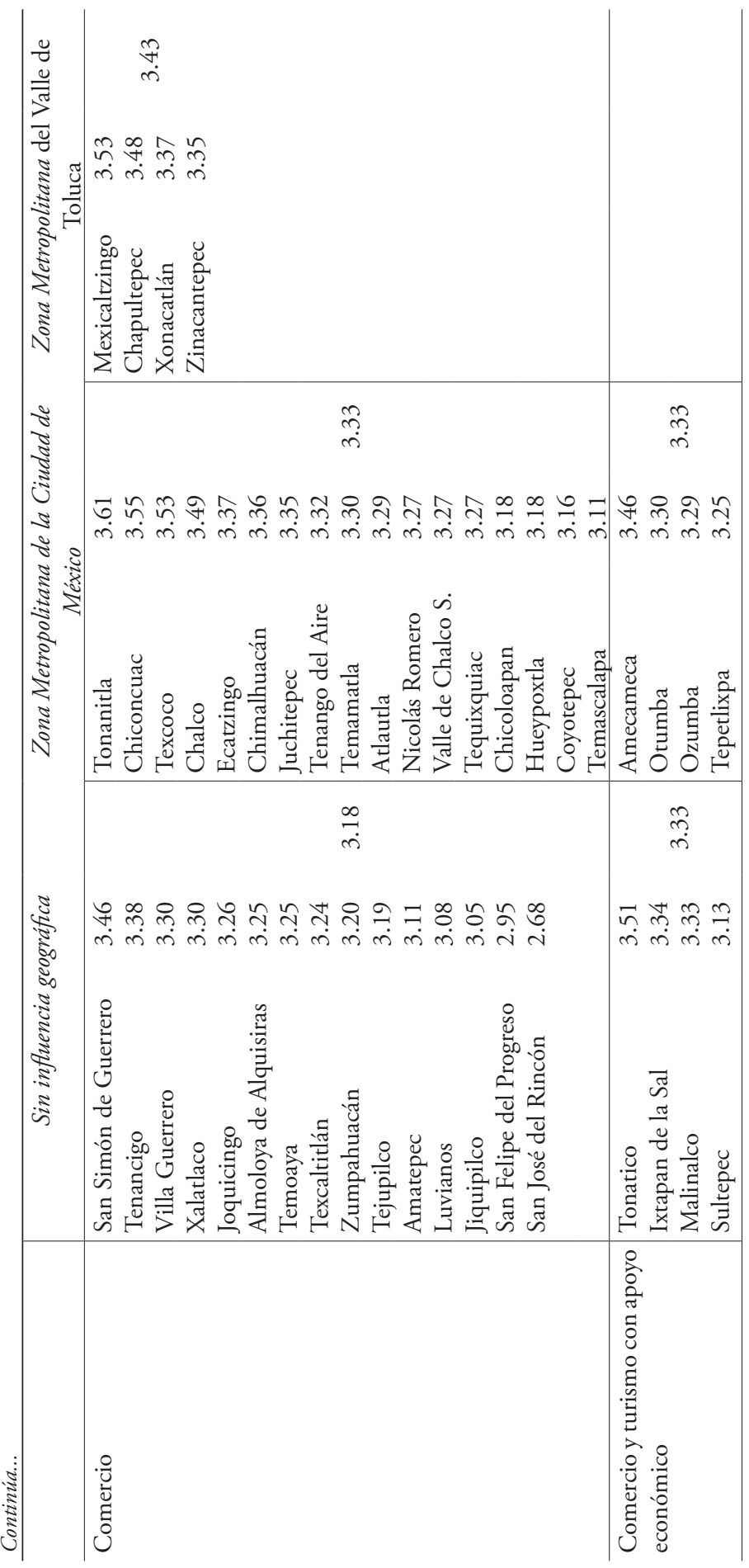




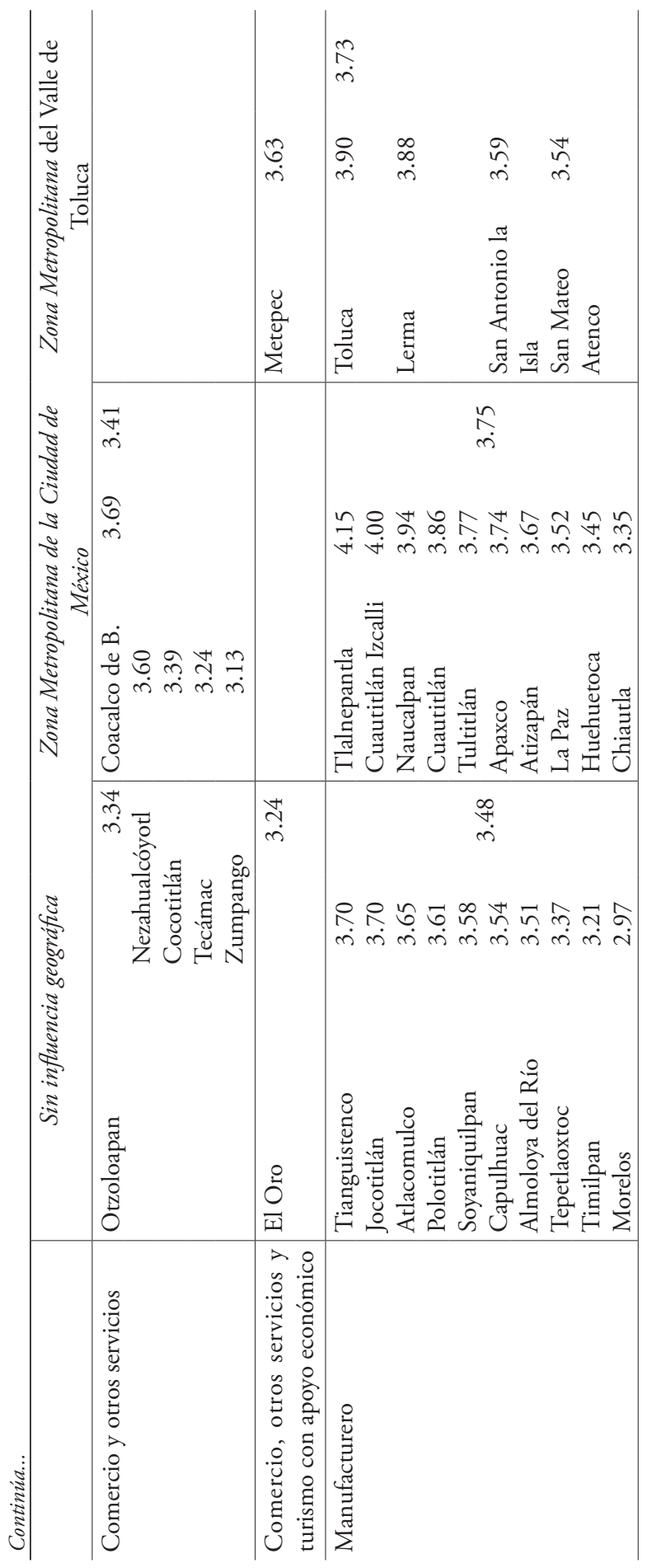




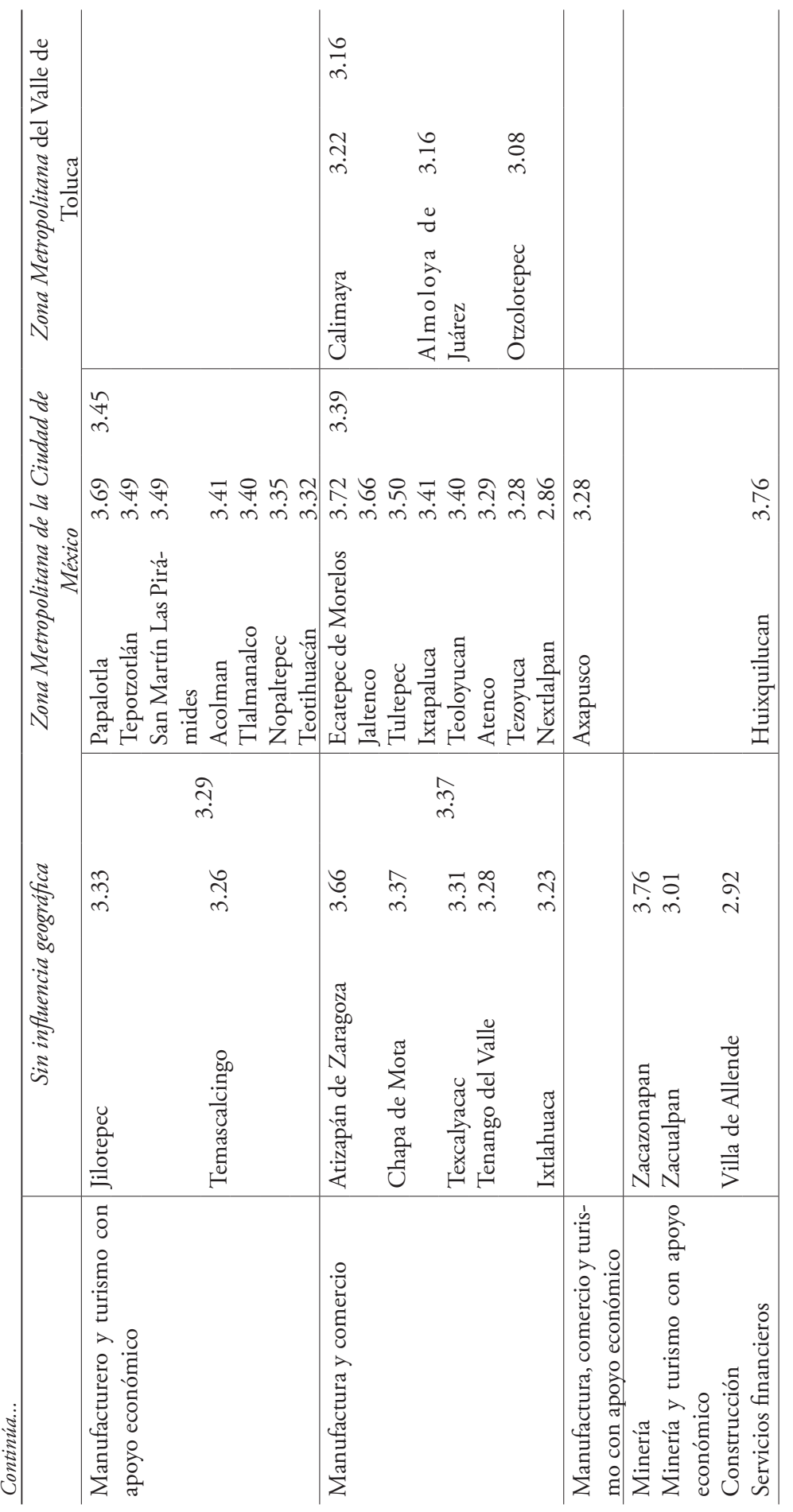




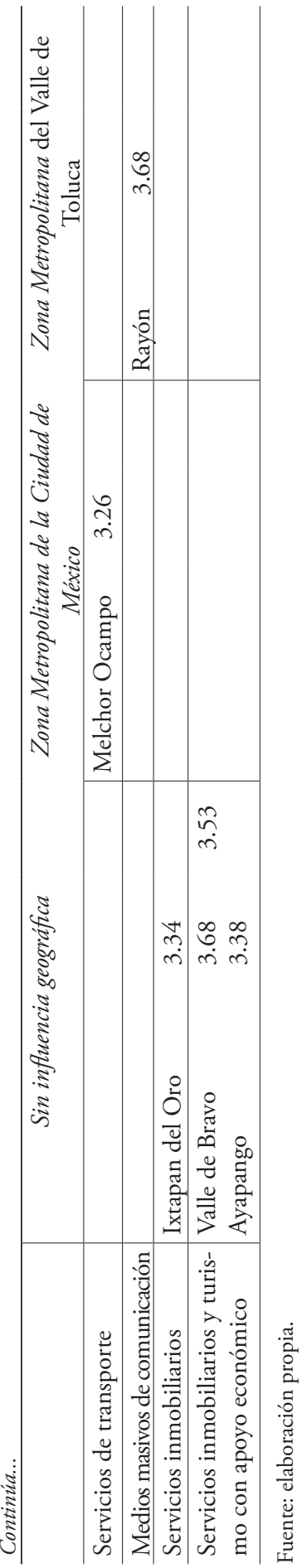


El municipio de Huixquilucan se ha beneficiado por su proximidad a la Ciudad de México, ya que las redes carreteras y de comunicación con las que cuenta han sido un atractivo para construir un corredor corporativo en donde las principales instituciones financieras del país, han establecido su sede.

A continuación se presenta el análisis de fortalezas y debilidades, de acuerdo a los factores con mayores y menores calificaciones que se incluyeron en el cálculo del indicador de competitividad municipal.

El análisis arrojó que los sectores con más debilidades son el agrícola y el minero; los sectores con más fortalezas son el comercial y el manufacturero. Cuando los municipios logran realizar ambas actividades el efecto es multiplicador. La ubicación es un factor determinante para la generación de un mayor o menor entorno competitivo: los municipios cercanos a grandes ciudades tienen mayor y mejor infraestructura carretera, educación y servicios médicos. Por tanto, también tienen una mayor densidad de población, lo que repercute incluso en la mayor asignación de recursos federales y estatales.

Se observa que las zonas rurales que se dedican a desarrollar actividades primarias son las que más requieren de infraestructura en educación y salud, así como mayor profesionalización (mayor educación superior), tecnificación de sus actividades para poder explotar con mayor eficiencia los recursos naturales. Los municipios dedicados a las actividades secundarias (manufactura), en general, también requieren de mayor infraestructura educativa y sanitaria, sobre todo si se considera que existen mayores riesgos de trabajo en este sector.

Los municipios que se han beneficiado de los programas de apoyo a las actividades turísticas no reportan como fortaleza un mayor PIB por servicios. Por otra parte, se sabe que para desarrollar muchos de los servicios turísticos se requiere energía eléctrica, por lo que parece contraproducente el hecho de que esos municipios no están reportando mayores recursos por electrificación. Una posible respuesta a ambas situaciones es que el sector informal está creciendo: por una parte, podrían surgir empresas turísticas que no están tributando y por otra, la posible conexión eléctrica de casas y negocios de manera clandestina.

\section{Conclusiones}

El desarrollo de un índice de competitividad a nivel municipal debe utilizarse para generar información que determine fortalezas y debilidades y, con ello, generar políticas públicas encaminadas a impulsar sus potencialidades. 


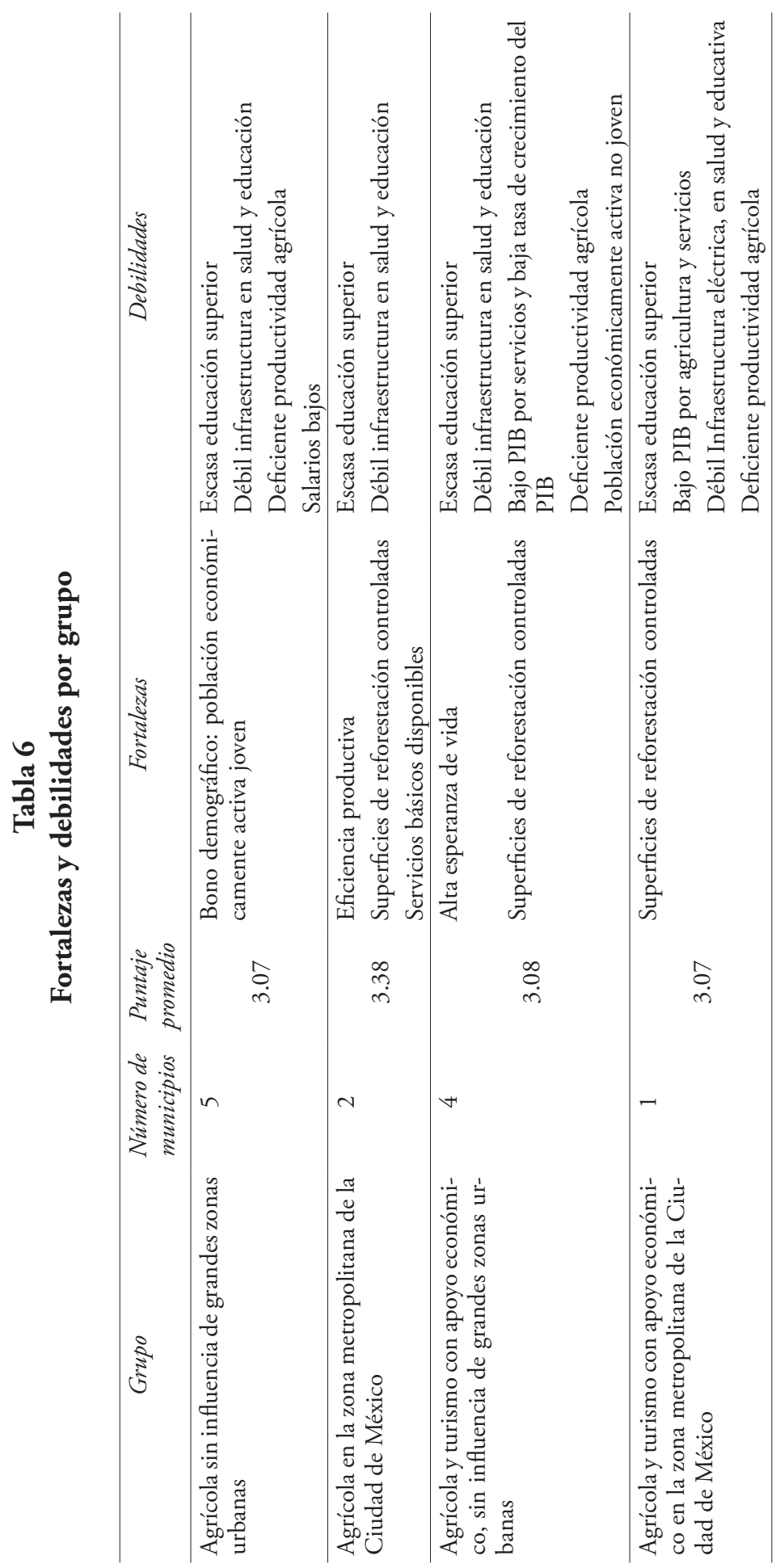




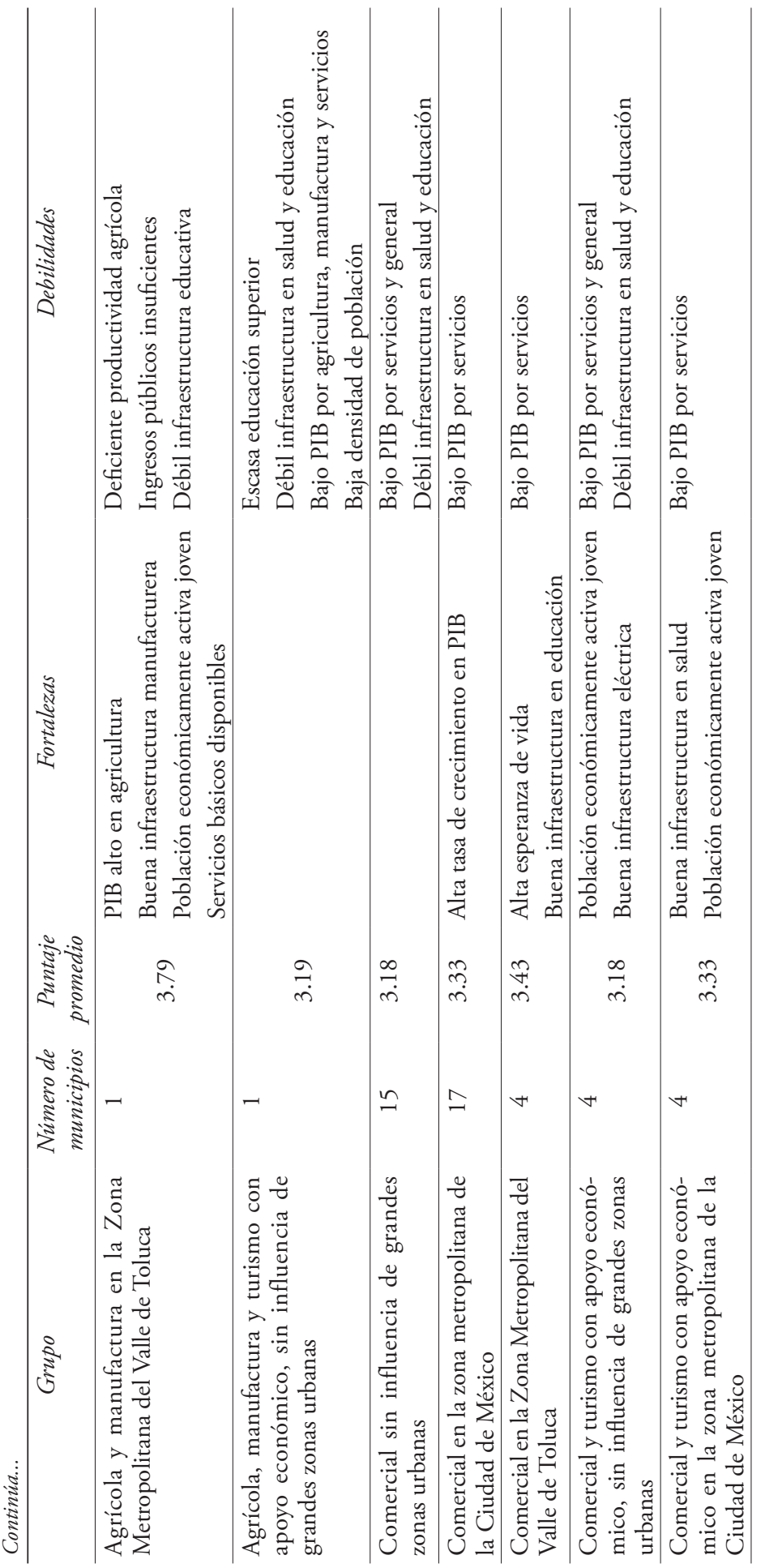




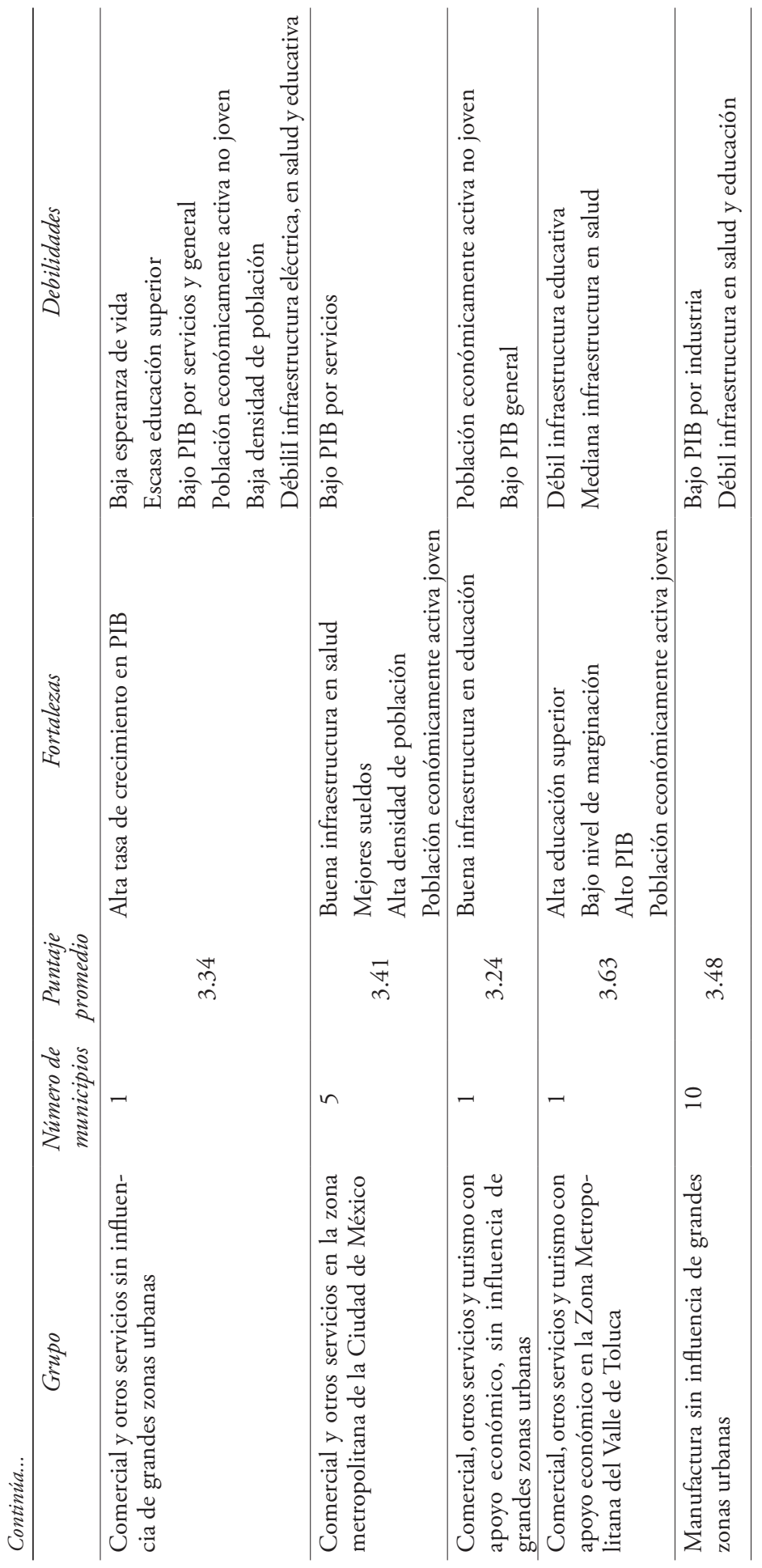




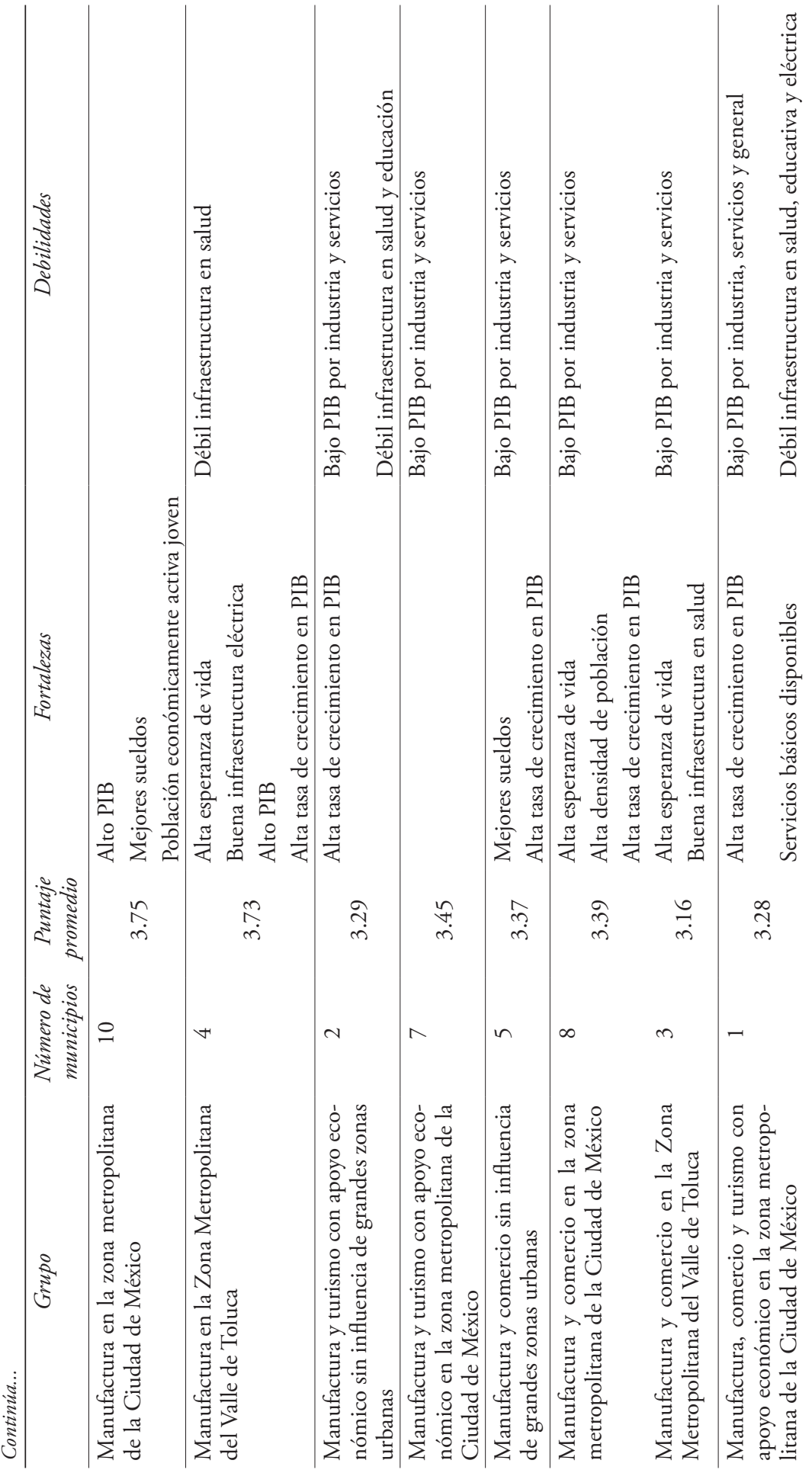




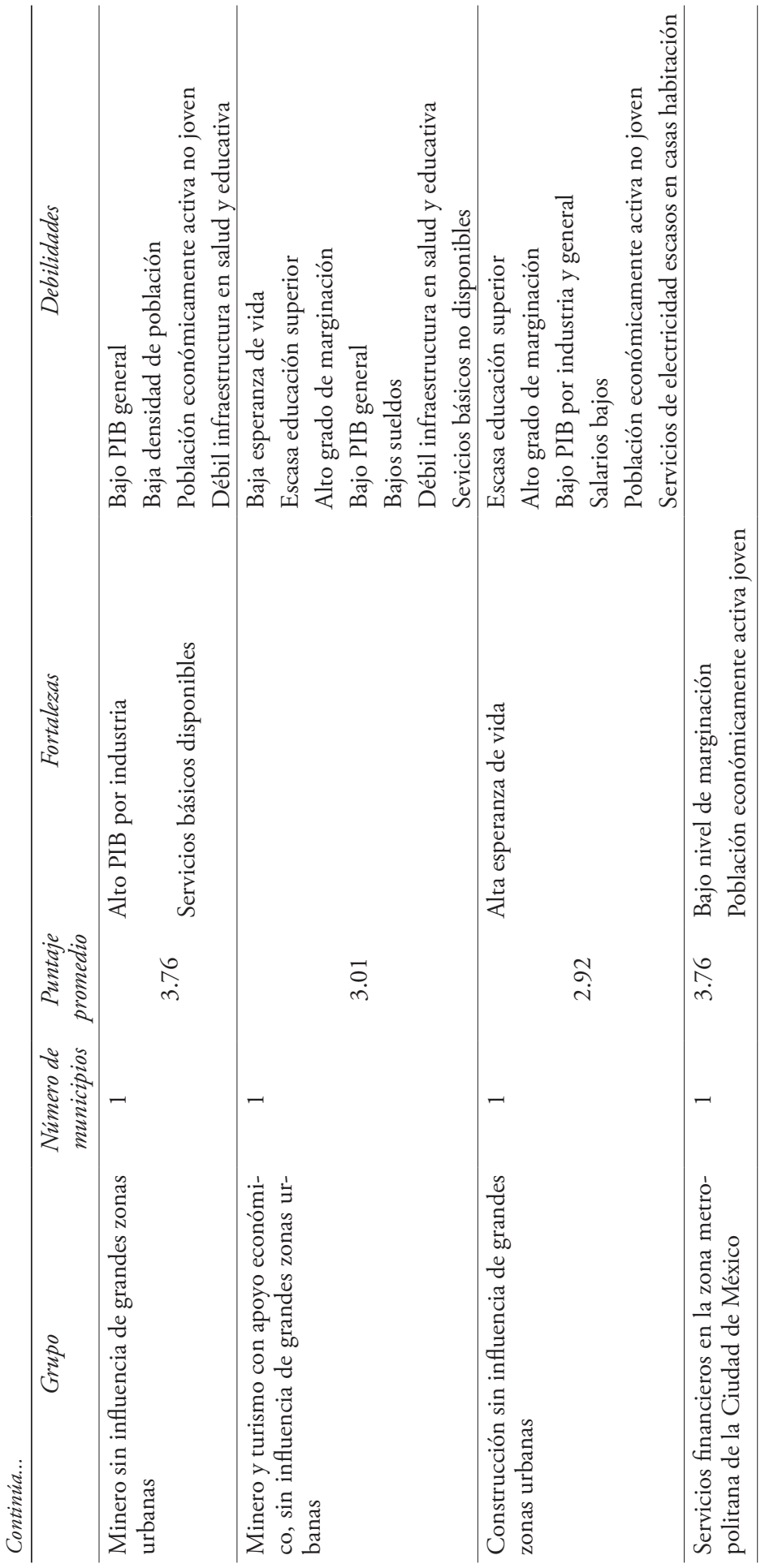




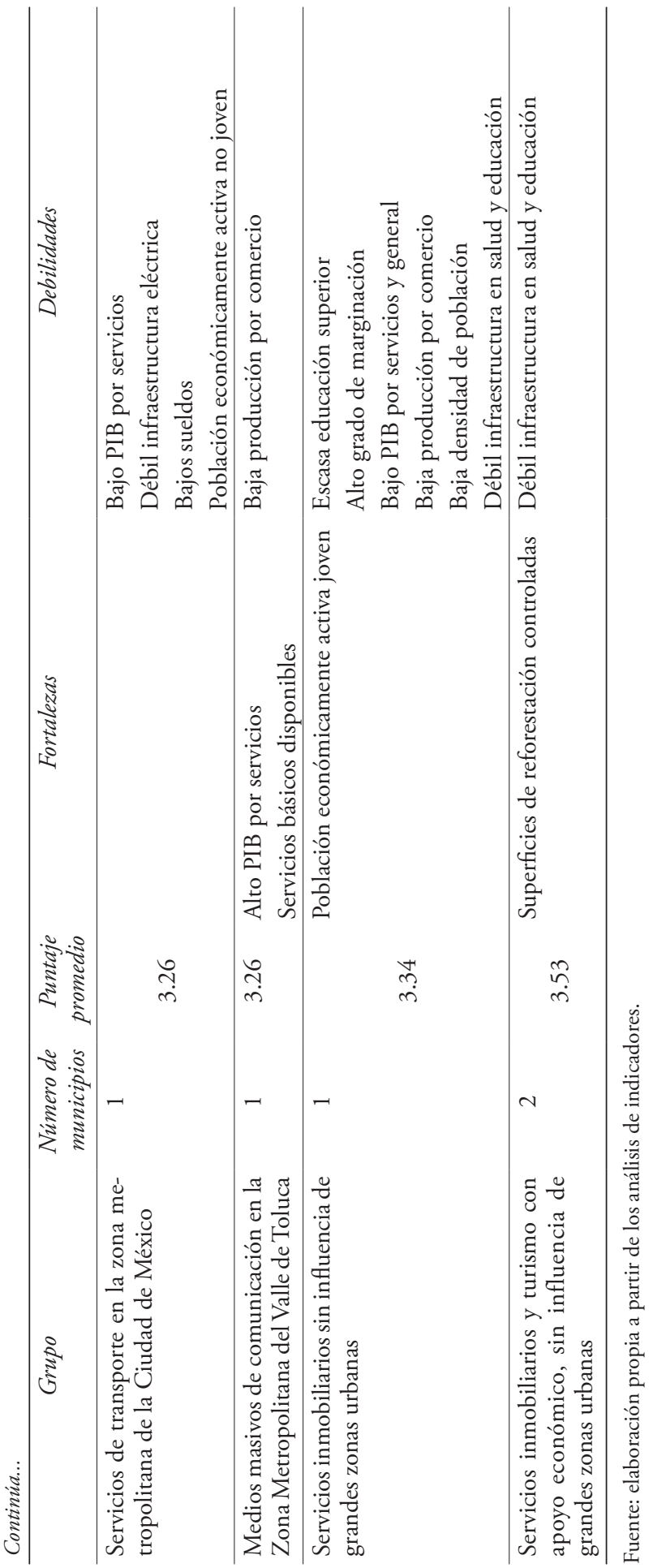


Si bien este ejercicio presenta limitaciones por la falta de información que, según los indicadores regionales de estudios internacionales, debe contener, puede ser un referente para construir y analizar los indicadores de competitividad municipal en otros estados de México y Latinoamérica. Al existir poca información a nivel municipal y ser poco transparente, un referente más objetivo son los datos publicados por el Inegi, ya que guarda cierta metodología y rigurosidad al recopilar dicha información.

Por ello, el indicador de competitividad municipal que aquí se desarrolla, sólo se basa en información estadística oficial. Sin embargo, como la construcción del indicador de competitividad municipal que se presenta en este trabajo se basó en estándares internacionales, queda fuera información importante como la preservación de culturas indígenas, la creciente presencia de la mujer en actividades económicas o la migración. Esto es una limitante que deja abierto el camino para investigaciones posteriores.

Un área de oportunidad para el Inegi es la recopilación de datos oficiales para construir un índice de competitividad regional según los estudios analizados, ya que no existe información sobre división del trabajo y especialización, calidad en bienes y servicios regionales, condiciones de empresas existentes, desarrollo empresarial, eficiencia del mercado laboral, infraestructura tecnológica, entorno social y ambiental, demanda del mercado, sofisticación de negocios, innovación, redes de cooperación entre ciudades y gobierno, calidad en educación, profesionalización de gobiernos locales ni inversión extranjera directa; existe información insuficiente sobre sistema legal y hay información relativa en el sector salud y educación superior.

Para construir un entorno más competitivo se tendrían que aprovechar las fortalezas que tienen los municipios en cada sector, se tendría que analizar la vocación a desarrollar tanto a corto como a mediano plazo. A manera de ejemplo, en los municipios que se encuentran en zonas rurales, es necesario impulsar el sector agrícola y ganadero con tecnología de punta y capacitación, a partir de la tecnificación y profesionalización para lograr una mayor eficiencia y desarrollo; con ello, puede frenarse la migración de la población rural hacia zonas urbanas. En las zonas mineras, la buena infraestructura carretera que tienen, podría aprovecharse para desarrollar otras actividades como el turismo, comercio y manufactura.

Por otro lado, deben desarrollarse políticas públicas que consideren las características particulares y la vocación de cada municipio. Las autoridades de los gobiernos federal, estatal y municipal (sobre todo los entrantes) deben observar estudios como el que aquí se presenta con el objetivo de planear, dirigir y controlar acciones prioritarias que permitan potencializar la competitividad de cada municipio. 
Algunas de las políticas públicas que deben priorizar los gobiernos deberán encaminarse al desarrollo de programas e incentivos que impulsen la instalación de empresas en municipios con similar vocación, así como la promoción y desarrollo de una cultura emprendedora y empresarial que permita potencializar sustentablemente los recursos de cada región. Es necesario, además, la generación de políticas públicas hacia la construcción de infraestructura y la elaboración de programas de estudio técnicos y universitarios que propicien el crecimiento y desarrollo de cada municipio según su vocación.

Uno de los factores fundamentales que consideran los estudios más recientes sobre competitividad regional es la infraestructura tecnológica, y es que en ella se considera el acceso a internet para reducir las brechas educativas y de salud, porque a partir de éste, puede desarrollarse infraestructura que acerque a mayor número de habitantes a la factibilidad de obtener educación de calidad. Además, ante la creciente demanda de servicios de salud y la poca oferta, la necesidad de profesionalizar a más personas y las asesorías que requieren los pequeños y medianos empresarios, el uso de la tele presencia que funciona con internet puede ser una solución viable para apoyar a los diferentes sectores, sobre todo en los municipios más alejados.

Sin embargo, dentro de los programas prioritarios, en prácticamente todos los municipios, debe contemplarse la construcción y mejoramiento de la infraestructura y equipamiento en salud y educación básica, media y superior, ya que son la base de un mejor entorno competitivo. Asimismo, la construcción de sistemas carreteros y de transporte para acercar servicios y generar mayores redes comerciales, puede contribuir a un mayor bienestar de los habitantes. La generación de energía sustentable y eficiente es fundamental, de esta manera llegaría a la mayoría de los habitantes de los municipios del Estado de México cuidando al entorno.

Complementariamente, es necesario fortalecer acciones que prevengan y combatan la delincuencia y corrupción para generar un entorno social estable y propicio para el desarrollo y operación de las políticas públicas mencionadas. En resumen, la construcción de un entorno competitivo puede lograrse si se conocen las potencialidades de cada municipio y, a partir de ello, se desarrollan políticas públicas que involucren los tres sectores de la población: gobierno, empresas y sociedad.

\section{Fuentes consultadas}

Annoni, Paola y Lewis Dijkstra (2013), EU Regional Competitiveness Index, European Comission, Joint Research Centre, Bruselas, Bélgica. 
Annoni, Paola y Kornelia Kozovska (2010), EU regional competitiveness Index, European Comission, Joint Research Centre, Luxemburgo.

Benzaquen, Jorge, Luis Alfonso del Carpio, Luis Alberto Zegarra y Christian Alberto Valdivia (2010), "Un índice regional de competitividad para un país”, Revista Cepal, 102, Comisión Económica para América Latina y el Caribe, Santiago de Chile, Chile, pp. 69-86.

Bonner, Karen (2007), "The competitiveness index: measuring and benchmarking northern Ireland's performance", The Northern Ireland Economic Bulletin, Department of Enterprise, Trade and Investment, Irlanda, pp. 27-35.

Cabrero, Enrique, Isela Orihuela y Alicia Ziccardi (2003), "Ciudades competitivas-ciudades cooperativas: conceptos claves y construcción de un índice para ciudades mexicanas", documento de trabajo núm.139, Centro de Investigación y Docencia Económicas, México, pp.1-46.

Carvalho, Luis, Leo Van Den Berg, Hazem Galal y Peter Teunisse (2017), "Organising capacity for sustainable urban competiteness", en Luis Carvalho, Leo Van Den Berg, Hazem Galal y Peter Teunisse (eds.), Delivering Sustainable Competitiveness. Revisting the organising capacity of cities, European Institute for Comparative Urban Research, Routlege Taylor \& Francis Group, New York, Estados Unidos de América, pp. 1-18.

Carrillo, Mario (2013), "Notas sobre la promoción del desarrollo en las regiones en México", ponencia presentada en el Congreso Regional en Administración CREA 2013, 26-27 de septiembre, Toluca, México.

Coneval (Consejo Nacional de Evaluación de la Política de Desarrollo Social) (2014), "Pobreza urbana y de las zonas metropolitanas en México", Coneval, México, <http://www.coneval.org.mx/Informes/Pobreza/Pobreza\%20urbana/Pobreza_urbana_y_de_las_zonas_metropolitanas_en_Mexico.pdf>, 22 de febrero de 2016.

Eckerson, Waine (2010), Performance dashboards: measuring, monitoring, and managing your business, The Data Warehousing Institute, San Diego, Estados Unidos de América. 
Esser, Klaus, Wolfgang Hillebrand, Dirk Messner y Jörg Meyer-Stamer (1996), "Competitividad sistémica: nuevo desafío para las empresas y la política", Revista de la CEPAL, 59, Comisión Económica para América Latina, Santiago de Chile, Chile, pp. 39-52.

Gobierno del Estado de México (2016), "Pueblos con encanto", Secretaría de Turismo, Toluca, México, <http://www.mispueblos.com. mx/pueblos_encanto_mexico>, 28 de septiembre de 2016.

Fuente de la, Ángel y María Gundín (2011), Indicadores de desempeño educativo regional: metodología y resultados para los cursos 2005-06 a 2007-08, Universitat Autónoma de Barcelona, Barcelona, España.

Guillermo-Peón, Sylvia Beatriz e Israel Gerardo García-Pérez (2015), "Índice de Competitividad Municipal 2013: metodología para su construcción basada en Análisis Factorial y su aplicación en municipios urbanos en México", Revista de Métodos Cuantitativos para la Economía y la Empresa, 20, Universidad Pablo de Olavide, Sevilla, Espańa, pp. 112-153.

Huggins, Robert (2003), “Creating a UK Competitiveness Index: regional and local benchmarking", Regional Studies, 37 (1), Sussex Innovation Centre, Falmer Brighton, Reino Unido, pp. 89-96.

Ibarra-Armenta, Cristina y Alejandra Trejo-Nieto (2014), "Competencia territorial: un marco analítico para su estudio", Economía, Sociedad y Territorio, XIV (44), El Colegio Mexiquense, A. C. Toluca, México, pp. 49-78.

Imco (Instituto Mexicano de la Competitividad) (2010), Índice de Competitividad Urbana 2010: acciones urgentes para las ciudades del futuro, Imco, A. C., México, <http://imco.org.mx/wpcontent/ uploads/2010/4/indice_de_competitividad_urbana_2010_acciones_urgentes_para_las_ciudades_del_futuro.pdf $>, 6$ de noviembre de 2015 .

Imco (Instituto Mexicano de la Competitividad) (2016), Índice de Competitividad Urbana 2016: reelección municipal y rendición de cuentas ¡cómo lograr el círculo virtuoso?, Imco, A. C., México, <http://imco.org.mx/wp-content/uploads/2016/09/2016- 
Indice_Competitividad_Urbana-Documento.pdf $>, 6$ de enero de 2017.

IMD (International Institute for Management Development) (2013), "The world competitiveness scoreboard 2013", IMD World Competitiveness Center, Lausana, Suiza.

Inegi (Instituto Nacional de Estadística y Geografía) (2010), "Censo General de Población y Vivienda”, Inegi, Aguascalientes, <http:// www.inegi.org.mx/sistemas/consulta_resultados/iter2010.aspx>, 6 de agosto de 2015.

Jiménez-García, Cecilia, Nidia López-Lira, Danielle Tomta, Ana Lilia Pacheco-Olvera (2011), "Competitividad de la economía mexicana, resultados en el periodo 1997-2007”, Convergencia. Revista de Ciencias Sociales, 18 (56), Universidad Autónoma del Estado de México, Toluca, México, pp. 215-238.

Kaiser, Henry (1974), "An index of factorial simplicity", Psychometrika 39, Springer, Nueva York, Estados Unidos de América, pp. 31-36.

Krugman, Paul (1994), Competitiveness: a dangerous obsession, Foreign affairs, 73(2), Council on Foreign Relations, New York, Estados Unidos de América, pp. 28-44.

Lévy, Jean-Pierre, Jesús Varela (2003), Análisis multivariable para las ciencias sociales, Prentice Hall, Madrid, España.

Linares-Zarco, Jaime (2012), "La importancia económica de los municipios en el México del siglo XXI", Revista Región y Sociedad, 24, El Colegio de Sonora, Hermosillo, México, pp. 35-61.

López, María Teresa y Natacha Gentile (2008), Sistema de indicadores económicos y sociales: la importancia del análisis integrado, Facultad de Ciencias Económicas y Sociales, Universidad Nacional de Mar del Plata, La Plata, Argentina.

Martin, Ronald (2003), "A study on the Factors of Regional Competitiveness. A draft final report for The European Comission Directorate-General Regional Policy”, University of Cambridge, Cambridge, Inglaterra, <http://ec.europa.eu/regional_policy/ 
sources/docgener/studies/pdf/3cr/competitiveness.pdf $>, 21 \mathrm{de}$ diciembre de 2015.

Martínez-Arias, María del Rosario (1995), Psicometría: Teoría de los tests psicológicos y educativos, Síntesis, Madrid, España.

Millán-Valenzuela, Henio y Martha Paola García-Pérez (2017), “Instituciones y desarrollo municipal: un análisis multinivel”, Economía Sociedad y Territorio, XVII (53), El Colegio Mexiquense, Toluca, México, pp. 63-86.

Önder, Irem, Karl Wöber y Bozana Zekan (2017), “Towards a sustainable urban tourism development in Europe: the role of benchmarking and tourism management information systems-A partial model of destination competitiveness", Tourism Economics, 23 (2), University of Limerick Ireland y Bournemouth University, Limerick, Irlanda, pp. 243-259.

Paulus, Fabien y Céline Vacchiani-Marcuzzo (2016), “Knowledge economy and competitiveness: economic trajectories of French cities since the 1960s", en Augusto Cusinato y Andreas PhilippopoulosMihalopoulos (eds.), Knowledge-creating milieus in Europe, Springer, Berlin-Heidelberg, Alemania, pp. 157-170.

Peñaloza, Marlene (2005), “Competitividad: ¿nuevo paradigma económico?", Revista Forum Empresarial, 10 (1), Centro de Investigaciones Comerciales e Iniciativas Académicas, San Juan, Puerto Rico, pp. 43-67.

PNUD (Programa de las Naciones Unidas para el Desarrollo) (2004), Índice de Desarrollo Humano Municipal en México, PNUD, México.

PNUD (Programa de las Naciones Unidas para el Desarrollo) (2010), Informe sobre Desarrollo Humano 2010, La verdadera riqueza de las Naciones: caminos al desarrollo humano, Ediciones MundiPrensa, Madrid, España, <http://hdr.undp.org/sites/default/files/ hdr_2010_es_complete_reprint.pdf>, 28 de febrero de 2016.

Porter, Michael (1991), La ventaja competitiva de las naciones, Vergara, Buenos Aires. 
Rodríguez-Yunta, Luis (1998), "Evaluación e indicadores de calidad en bases de datos", Revista Española de Documentación Cientifica, 21, Consejo Superior de Investigaciones Científicas, Madrid, España, pp. 9-23.

Romo, David y Guillermo Musik (2005), "Sobre el concepto de competitividad", documento de trabajo núm. 55, Centro de Estudios de Competitividad del Instituto Tecnológico Autónomo de México, Ciudad de México, México, pp. 200-214.

Ronquillo-Rodríguez, David (2013), "Índice de c ompetitividad para los municipios del Estado de México (2010-2012): una propuesta para su medición”, tesis de grado de maestro en finanzas, Universidad Autónoma del Estado de México, Toluca, México.

Rubí-Salazar, José Adán Ignacio (2007), Competitividad: base para el diseño, ejecución y evaluación de políticas públicas, Gobierno del Estado México, Biblioteca Mexiquense del Bicentenario, Toluca, México.

Ruiz, Miguel y Rafael San Martín (1992), "Una simulación sobre el comportamiento de la regla K1 en la estimación del número de factores", Psicothema 4, Colegio Oficial de Psicólogos del Principado de Asturias, Oviedo, España, pp. 543-550.

Schwab, Klaus (2013), "The global competitiveness report 2013-2014”, The World Economic Forum, Ginebra, Suiza.

Schwab, Klaus y Michael Porter (2009), "The global competitiveness report 2008-2009”, The World Economic Forum, Ginebra, Suiza.

Secretaría de Turismo (2016), "Pueblos mágicos de México", Secretaría de Turismo, Ciudad de México, México, <http://www.pueblosmexico.com.mx>, 16 de diciembre de 2016.

Sobrino, Jaime (2005), "Competitividad territorial: ámbitos e indicadores de análisis", Economía Sociedad y Territorio, Edición especial, El Colegio Mexiquense,Toluca, México, pp. 123-183.

Taibo, Carlos (2009), En defensa del decrecimiento: sobre capitalismo, crisis y barbarie, Los libros de la Catarata, Madrid, España. 
Thurstone, Louis Leon (1947), Multiple factor analysis, University of Chicago Press, Chicago, Estados Unidos de América.

Van Horne, James, Julio Pando y Luis Martínez (1988), Administración financiera, Prentice Hall, Naucalpan, México.

Velázquez, Guillermo, Humberto Merrit, Abraham Navarro y Erika Alfaro (2011), La competitividad desde una perspectiva regional y empresarial en el Estado de México, Secretaría de Desarrollo Económico, Gobierno del Estado de México, Toluca, México.

WEF (World Economic Forum) (2009), "The Global Competitiveness Report 2008-2009”, The World Economic Forum, Cologny, Suiza, <http://www3.weforum.org/docs/WEF_GlobalCompetitivenessReport_2008-09.pdf>, 15 de octubre de 2015.

WEF (World Economic Forum) (2015), "The Global Competitiveness Report 2014-2015”, The World Economic Forum, Cologny, Suiza, <http://www3.weforum.org/docs/WEF_GlobalCompetitivenessReport_2014-15.pdf>, 15 de marzo de 2016.

Recibido: 8 de agosto 2015. Corregido: 27 de enero de 2016. Aceptado: 29 de agosto de 2016.

Rosa María Nava-Rogel. Es Doctora en Ciencias Económico Administrativas por la Universidad Autónoma del Estado de México (UAEMéx). Profesora investigadora de tiempo completo en la Facultad de Contaduría y Administración de la UAEMéx, iniciadora de la Red Nacional de Estudios Económico Administrativos. Líneas de investigación: competitividad, educación superior y capital intelectual. Últimas publicaciones, en coautoría: "El valor explicativo del turismo sobre las actividades con mayor contribución en el crecimiento económico de los municipios del Estado de México", El Periplo Sustentable, 17 (33), Universidad Autónoma del Estado de México, Toluca, México (en prensa); "La interdisciplinariedad económico-administrativa en la conformación de una comunidad científica y la formación de investigadores", Revista de la Educación Superior, 45 (177), ANUIES, Ciudad de México, México, pp. 43-65 (2016); "Los stakeholders de la industria hotelera: una clasificación a partir de sus intereses ambientales", Revista Universidad y Empresa, 18 (30), Universidad del Rosario, Colombia, pp. 97-120 (2016); "Alterna- 
tivas de gestión de capital Intelectual en las instituciones de educación superior. Una propuesta para su evaluación", Cuadernos de Administración, 32 (55), Universidad del Valle, Colombia, pp. 47-58 (2016).

Daniel Arturo Cerna-Ortiz. Profesor-investigador de tiempo completo de la Facultad de Contaduría y Administración de la UAEMéx. PhD in Management por la Universidad del Norte de Texas, donde, además de estudiante, fungió como profesor de asignatura y asistente de investigación. Pertenece al Sistema Nacional de Investigadores desde 2013. Integrante del Cuerpo Académico Gestión del Capital Intelectual. Áreas de interés: administración estratégica y comportamiento humano en la organización. Entre sus últimas publicaciones destacan, en coautoría: "Influencia del capital relacional en el desempeño organizacional de las instituciones de educación superior tecnológica", Innovar, 26 (60), Universidad Nacional de Colombia, Colombia, pp. 35-50 (2016); "La relación entre los beneficios de un ERP y el desempeño de la empresa: análisis del efecto del capital humano y el capital social", Revista Internacional de Economía y Gestión de las Organizaciones, 4 (1), Common Ground Publishing España, España, pp. 45-59 (2016); "Future and past negative time perspective influences on job satisfaction and organizational commitment in Mexico and the United States", Management Research: Journal of the Iberoamerican Academy of Management, 14 (3), Emerald Group Publishing Limited, Armonk, New York, Estados Unidos de América, pp. 317-338 (2016).

Osvaldo Urbano Becerril-Torres. Es doctor en ciencias económico administrativas por la UAEMéx. Profesor-investigador de la Facultad de Economía de la UAEMéx. Miembro del Sistema Nacional de Invstigadores, nivel I, e investigador del Centro de Investigación en Ciencias Económicas. Sus líneas de investigación son eficiencia técnica, productividad total de los factores, convergencia, Infraestructuras y análisis sectorial y regional. Entre sus últimas publicaciones destacan, en coautoría: “¿Es óptimo el uso de los factores productivos en México? Una respuesta a través del análisis de fronteras estocásticas”, Investigación y Ciencia, 22 (62), Universidad Autónoma de Aguascalientes, Aguascalientes, México, pp. $42-48$ (2014); "Eficiencia técnica de las entidades federativas de México", Economía Sociedad y Territorio, 10 (33), El Colegio Mexiquense, Toluca, México, pp. 485-511 (2010); "Efecto de la globalización sobre la eficiencia técnica en el contexto regional de Colombia", AD-minister, (22), Universidad EAFIT, Medellín, Colombia, pp. 9-31 (2013); y "Frontera tecnológica y productividad total de los factores de las regiones de México”, Región y sociedad, 25 (57), El Colegio de Sonora, Hermosillo, México, pp. 5-26 (2013). 